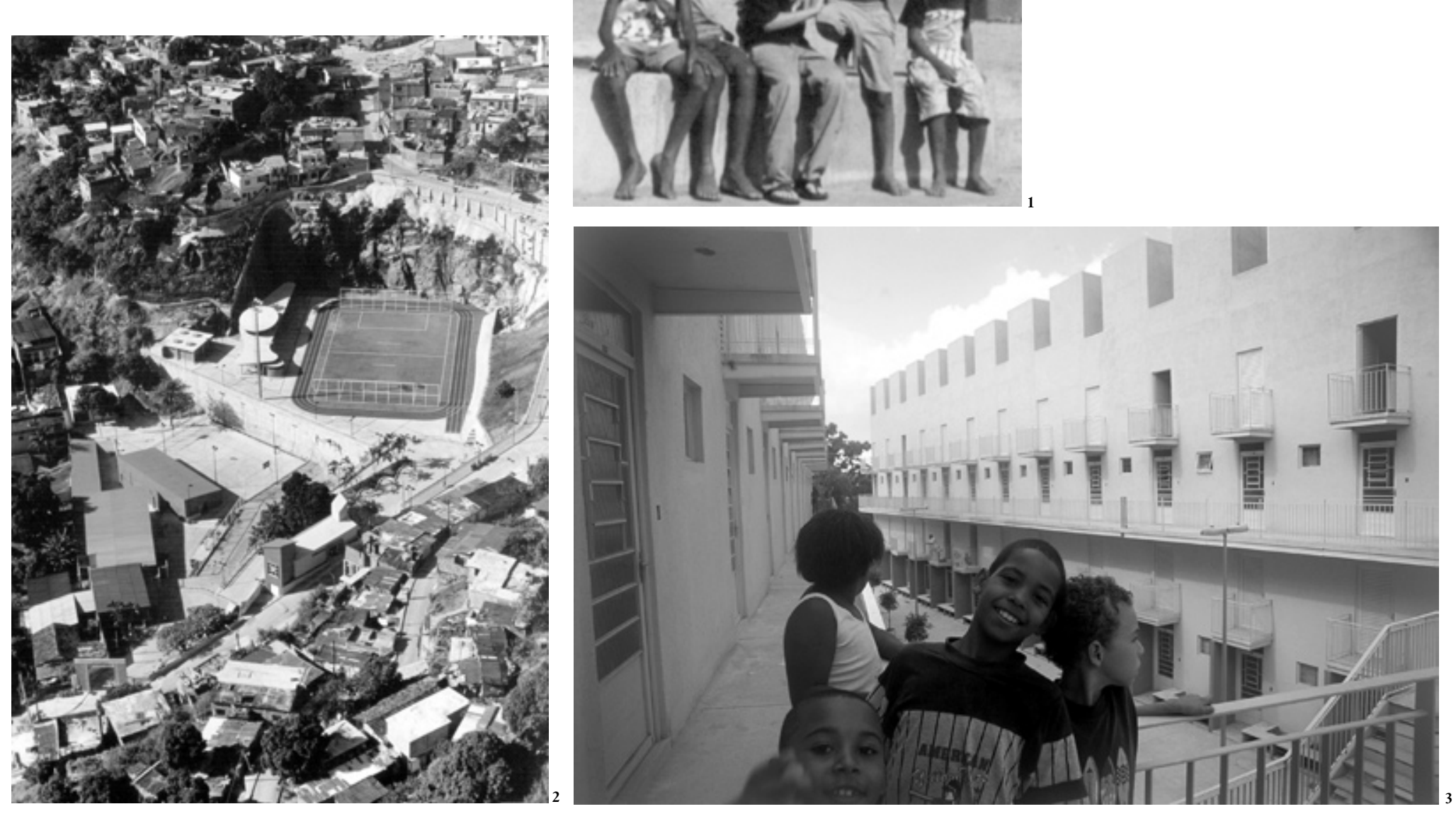

Jorge Jáuregui
Rio de Janeiro, Brasil

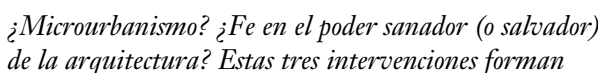
de la a rquititectura? Estas tres intervenciones forman
parte del provecto "Favel Bairro", una inciativa que

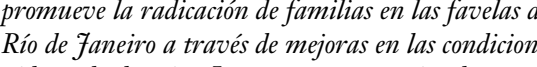

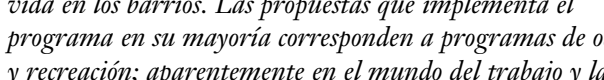
y recreación; a aparentemente en el mundo del trabajio y la
productividad no estan las inicas respuestas a los problema

Vicro-town-planning? Faith in the bealing (or soving?)

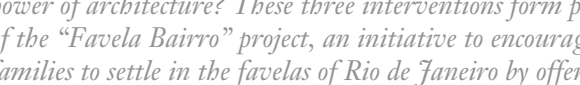
etter living conditions in their neighbortboods. The

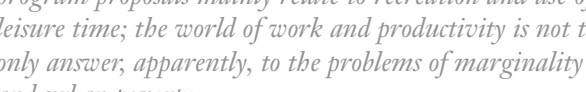

\section{3 proyectos en favelas}

El juego como procedimiento proyectual relación "con el cliente" (en los proyectos aquí 政 disposición de las partes, que buscan su "encije" cierto nivel de "ijuego" también en el ceatido centes, en que por momentos se produce un diálogo segun una cierta logica ordenadora. creativo, que determina una transferenciaia, una Jacques Lacan dice que lo que diferencia puesta en contacto de distintas subjetividades. ha más allá de lo que el edificio soporta de posible en la propia configuración fontestacho utilización. Y dice tambien que esta logica no se armoniza con la eficacia sino para dominarla y que su discordia no es, en el arte de la 3 proyectos: Edificio de usos comunitario esta "potencia lópica ordenadora” que viene La Vilh Olímica y el edificio de de afuera, no de la propia "función". En este comunitarios forman parte del proyecto de sentido sabemos que la forma no sigue a la integración urbanística y social de un áre

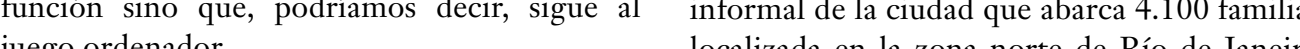
$\begin{array}{ll}\text { juego ordenador. } & \text { localizada en la zona norte de Río de Janeiro. } \\ \text { Pero también podríamos pensar que la propia } & \text { Fl espacio de convivencia está localizado en }\end{array}$

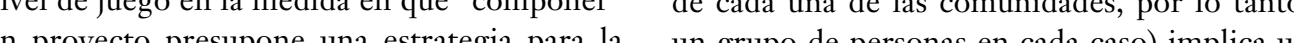

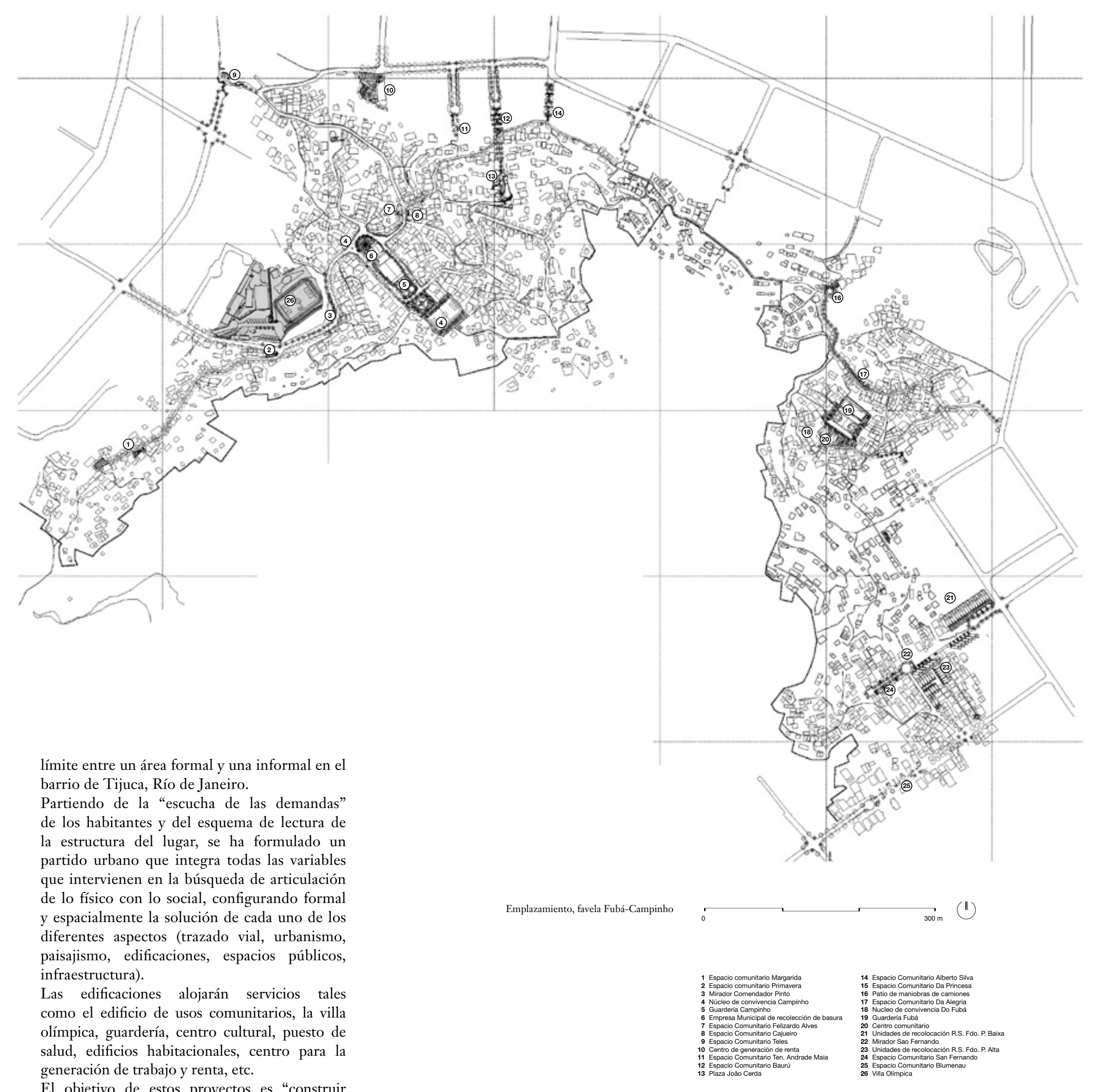

generación de trabajo $y$ renta, etc.

El objetivo de estos proyectos es "construir
ciudad", incorporando edificaciones y espacio de uso público capaces de actuar como soporte para la evolución y la integración social. 

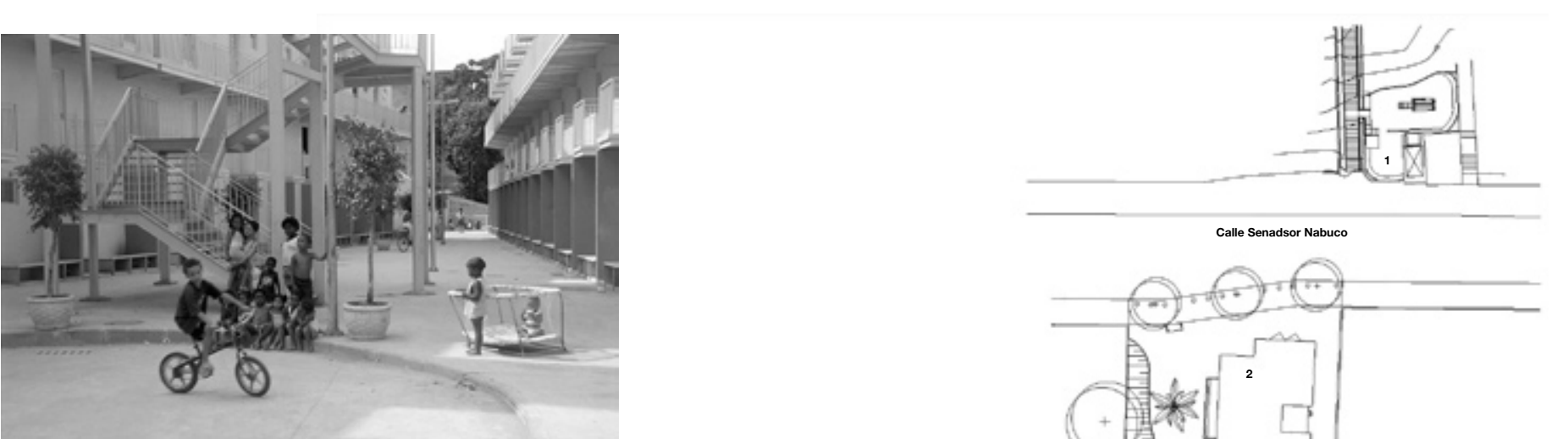

$\underset{36}{A R Q}$
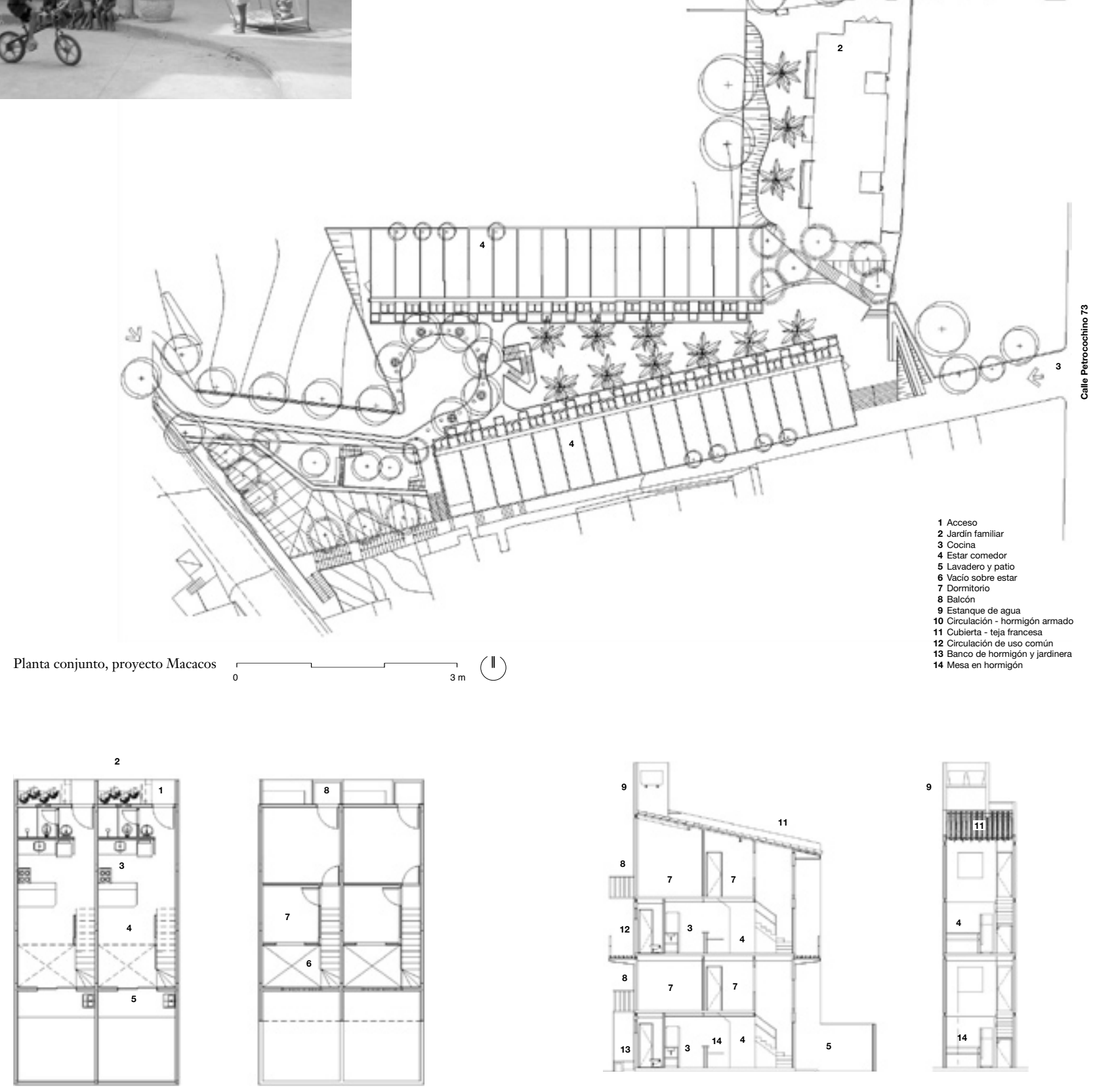

20.02

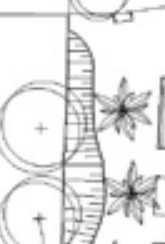

+

Planta blogueses y uniddedes de vivienda, $1^{\circ} y^{\circ} p^{p}$ iso
Coret longitudinal y yranserersal, unidades de vivienda

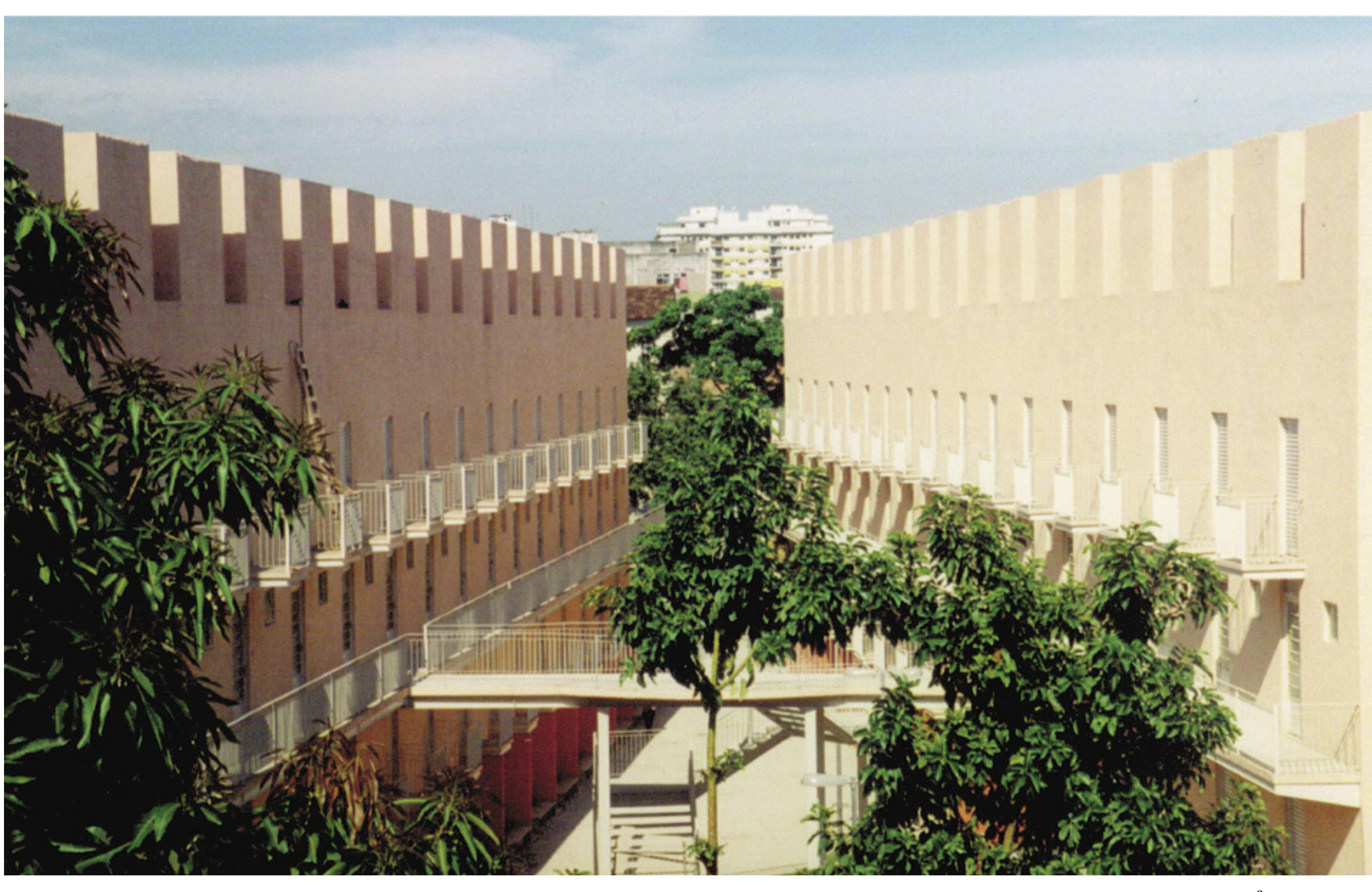

Espacio de convivencia en Macacos

El núcleo residencial es aquí utilizado desde su termina en la puerta "de calle" sino que se amplía que en sus varios ángulos y sombras retoma la $\begin{array}{llll}\text { colectivo. El programa es dividido en dos bloques de } & \text { de acceso al barrio, se accede por un pasaje que } & \text { distancia, el congestions es situa frente al vertice más cerrado de un } \\ \text { de las áreas informales, es atenuado por este perfil }\end{array}$ lepartann Hoste El espacio entre los bloques crea formalmente mos atenuada, por esta implantación geométrica páblica de la vida comunitaria que tiene en un camino alternativo y privilegiado para irregular, como transición entre la ciudad formal y los trayectos entre las edificaciones el mayor los habitantes y un generoso espacio para la la informalidad de la favela. lugar de encuentros y en la proximidad de las convivencia que contine una pequeña plaza de El remate de las fachadas en solidos intercalados construcciones la seguridad de estar viviendo en Tercera
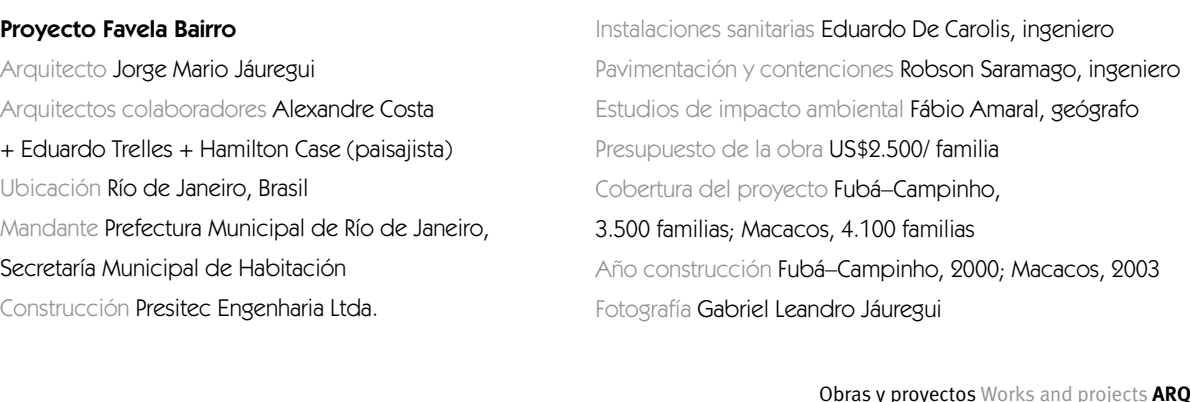